\title{
sciendo
}

\section{Files, Indexicals and Descriptivism}

\author{
Krista Lawlor \\ Stanford University \\ DOI: $10.2478 /$ disp-2013-0014 \\ BIBLID [0873-626X (2013) 36; pp. 147-158]
}

Recanati's book contains stimulating discussions of a great many interesting problems and repays careful reading. My comments focus on some questions about indexicals and descriptions.

Recanati defends Singularism against Descriptivism. The Singularist claims (i) the semantic contribution of a referring term to the proposition expressed by an utterance in which it figures is its referent; (ii) one needs acquaintance with, or more generally an epistemically rewarding (ER) relation to the referent, if one is to think a singular thought about it. On Recanati's view, Singularists can better defend these two theses by including mental files in their account, using files to play the roles usually assigned to modes of presentation.

Descriptivism denies (i), holding that referring terms contribute descriptive content to the proposition expressed, where this content in turn determines reference. Descriptivism runs into trouble, according to Recanati, because it neglects the 'relational character of reference determination' (22). He makes a good point here - this neglect is arguably the root of Descriptivism's vulnerability to the socalled 'modal argument.' But of course Descriptivism can be modified to address the problem by injecting relational properties into the descriptive content associated with a referring term. ${ }^{2}$ For example, one sees Mt. Blanc and thinks 'that peak is dramatic.' The amended

${ }^{1}$ Marcus 1961; Kripke 1980.

${ }^{2}$ Searle 1983. Alternatively the Descriptivist might hold that rigidified descriptions 'the actual F', or 'dthat F' are the semantic contribution of names and other referring terms (Kaplan 1970). But here, Recanati argues, because it is possible for 'the actual F' to be used attributively, the hearer or consumer of the sentence might understand it without knowing what the sentence refers to. So rigidified descriptions cannot secure the hearer's grasp of a singular thought about the particular $F$ in question.

Disputatio, Vol.V, No. 36, October 2013 
Descriptivist view holds that the demonstrative 'that peak' contributes a description of a relation between the thought (or thinker) and the referent - for instance, 'the peak causing this visual experience' or 'the peak I see.'

Recanati argues that the resulting 'sophisticated 2-D Descriptivism' still fails. He raises two objections, one about the communication of singular thought and one about the fact that Descriptivism internalizes acquaintance relations. Thinking about both objections helps us to see more deeply into Recanati's own project.

\section{Descriptivism and the communication of singular thoughts}

Recanati's first objection to sophisticated Descriptivism is that it fails to account for a constraint on the communication of singular thoughts:

'First, to grasp the singular thought expressed by an utterance such as 'That peak is less than $4000 \mathrm{~m}$ high', it is not sufficient for the hearer merely to understand that the speaker is looking at a (unique) peak and saying of it that it is less than $4000 \mathrm{~m}$ high: the hearer herself must come to occupy an epistemic position enabling her to entertain a singular thought about the same object. As we have seen, entertaining such a thought involves standing in a suitable ER relation to the object of the thought. (Typically, the hearer will have to look in the same direction as the speaker, in order to see the peak for herself.) ${ }^{3}$ This constraint on what counts as understanding in the singular case is left unaccounted for by 2-D Relational Descriptivism.' (24)

Recanati's basic claim is that grasping a relational descriptive content does not ensure that the hearer will stand in a suitable ER relation to the object; but standing in such a relation is required for understanding. More fully, his argument is this:

(i) Entertaining a singular thought requires standing in an ER relation to the referent.

(ii) If a hearer understands a communicated singular thought, then the hearer must stand in an ER relation to the same referent to which the speaker stands in an ER relation. (Recanati's 'constraint'.)

\footnotetext{
${ }^{3}$ Recanati here cites Strawson (2004: 78).
} 
(iii) But a hearer might understand the communicated Descriptivist content perfectly well without standing in an ER relation to the referent.

(iv) So a hearer might understand the communicated Descriptivist content, and yet not thereby be enabled to think a singular thought with the referent as its object.

(v) So the Descriptivist content is insufficient as an analysis of the content of the singular thought.

To illustrate, imagine that the speaker's utterance 'That peak is less than $4000 \mathrm{~m}$ high' is recorded and replayed at some other time and location. Hearers of the recording would understand that the mountain the speaker is seeing is $F$. But they wouldn't thereby grasp a singular thought about Mt. Blanc. Why? There are arguments about what a singular thought is and what it takes to think one. Without entering into these arguments, we might propose a neutral criterion or test for when a speaker has communicated a singular thought. The criterion is that the hearer thereby be in a position to corefer with the speaker, that is, to make anaphoric reference to the object of the speaker's thought. In the recording case, the hearer is not in a position to make an anaphoric reference to Mt. Blanc. ${ }^{4}$

Using this neutral criterion, we can see if the Descriptivist might reply to Recanati's argument. To reply to the argument, the Descriptivist must specify a relational descriptive content that the speaker might convey to the hearer which would permit the hearer to take up the speaker's reference to Mt. Blanc, and to make anaphoric reference to it with her own utterances. For example, if the hearer might grasp the content of the speaker's utterance and go on to appropriately say, 'Yes, and it's covered in snow, too', then it will count as a case of successful communication of singular thought.

\footnotetext{
${ }^{4}$ We should probably add that the test involves 'non-lazy' anaphora, where one isn't just using an anaphor as a shortcut to duplicate some content expressed by the speaker, but uses the anaphor in an 'essential' way to corefer. Thanks to David Hills for suggesting (though not necessarily advocating) the proposed criterion.
} 
Here's a try on behalf of the Descriptivist. Suppose the hearer is on the phone with the speaker, and when the speaker says, 'that peak is less than $4000 \mathrm{~m}$ high', the hearer grasps the descriptive relational content the mountain you are seeing is less than $4000 \mathrm{~m}$. The hearer has descriptive information about the situation of the speaker as the speaker is talking. The hearer thinks of the referent of 'the speaker' (or 'you') under the relational description the person talking to me now, and the referent of 'here' (should the speaker use it) under the description the location of the person talking to me now. These are thin descriptions, but they give the hearer a handle on the situation of the speaker. And it seems that grasping these descriptive contents gives the hearer a sufficiently tight handle on the speaker's situation so that she can refer to what he refers to anaphorically. In the case we're imagining, it is possible for the hearer to take up the speaker's reference anaphorically. When the speaker reports, 'that peak is less than $4000 \mathrm{~m}$ high', the hearer may reply, 'Is it less than even $3000 \mathrm{~m}$ do you think?'

More needs be said to establish that a Descriptivist response along these lines might work. Obviously the Descriptivist owes an explanation of why having a relational descriptive take on the situation of the speaker permits the hearer to corefer with the speaker's utterance. ${ }^{5}$ My aim here is just to suggest that it seems the Descriptivist may have the resources to respond to Recanati's complaint.

The envisioned Descriptivist response raises further issues about the communication of indexical thought. The communication of indexical thought is a large topic for Recanati because on his view much of our thought about objects is indexical: we entertain non-descriptive thoughts by standing in contextual relations to the objects the thoughts are about. And so the question how we can communicate such thoughts to hearers in different contexts becomes pressing for Recanati (166).

Recanati notes that Frege addresses the question of the communication of indexical thought by distinguishing private ("psychological') modes of presentation and publicly communicable ('linguistic') modes of presentation; we cannot communicate the private mode of presentation, though we can communicate the public one (167 ff).

\footnotetext{
${ }^{5}$ Again, not just in a 'lazily' anaphoric way.
} 
But as Recanati notes, this only invites the question: how are these modes related?

Recanati ultimately prefers a different answer than Frege's. The idea is that when indexical thought is communicated the speaker and hearer have more in common than a state of affairs they both represent. ${ }^{6}$ Crucially, the modes of presentation under which speaker and hearer think about the state of affairs also have some content in common (171).

For example, Sam tells Helen, 'The mountain I see is F' and Helen thereby comes to think the mountain you see is $F$. The indexicals ' $I$ ' and 'you' have 'descriptive meanings' (176) such as 'the speaker of utterance $u$ ', 'the hearer of utterance $u$ ', which in turn are part of the content of the relevant files or modes of presentation. Suppose both Sam and Helen have a file concerning Sam, and each of their files contains the information that Sam is the utterer of the token. It is this overlapping content that ultimately makes communication possible. The full story from here is somewhat complex. (Briefly, when Sam says, 'the mountain I see is F' he expresses a thought with his file on himself as a constituent, because he associates the descriptive meaning 'the speaker of the utterance' with 'I' (176). Helen, the hearer, also associates this descriptive meaning with Sam's utterance of 'I', and in her case, this same descriptive meaning triggers her file on Sam, and makes it a constituent of her thought.) Details aside, the crux of Recanati's view is that the descriptive meanings of indexicals provide 'identificatory facts' (172) about their associated referents, and the sharing of these meanings is what makes possible communication involving indexicals.

Recanati's account deserves more discussion than I can give it here. For our purposes, we should note just one thing. As we saw, in order to make sense of how communication with indexicals works, Recanati claims that each indexical has associated descriptive meaning, which provides 'identificatory facts' about the referent of the indexical term. Both speaker and hearer have files on the referent, and these descriptive meanings are part of those files. Now it's a good question for Recanati whether by locating these descriptive

${ }^{6}$ The state of affairs is in turn is represented by a Russellian proposition (or the 'subject matter proposition' in Perry 2001). 
meanings in the thinker's file he takes his own view a step toward 'internalizing acquaintance relations.' For recall that Recanati's second main charge against Descriptivism is that it implausibly 'internalizes' acquaintance relations, incorporating them into the content of thought (34). Let's turn to that complaint now.

\section{Internalizing acquaintance}

Recanati's second main complaint against Descriptivist accounts of singular thought is that they make the relation between thinker and object an element in the content of the thought. This over-intellectualizes singular thought.

Does Recanati's own view manage to steer away from internalizing acquaintance as completely as he wishes? There are two places where it seems the files account must allow acquaintance relations to be accessible to thinkers.

(a) The first, as we just saw, is in Recanati's account of indexicals in communication. Recanati's solution requires including the descriptive meaning of ' $\mathrm{I}$ ' in the file content: it requires that this meaning provide identificatory facts about the referent (the speaker), and it requires that the descriptive meaning is consciously accessible (both to speaker and to hearer).

(b) The second place where internalization is suggested is this. Consider the idea that a file serves as a mode of presentation. When Earl remembers seeing the Louvre, he has a memorial mode of presentation of the Louvre; when he sees the Louvre, he has a visual mode of presentation. The files account says Earl has two files (or in more complex cases, where Earl knows it is one and the same museum in question, there are two files that are linked, or (eventually perhaps) there is but one file based on two ER relations). Now suppose Earl remembers the Louvre. When he thinks 'What a large building that was', he thinks with a memorial mode. That this mode of presentation is different than the visual mode of presentation he once enjoyed is plain to him. If Earl is a normal adult, he is probably able to articulate this fact. Earl probably doesn't express the difference by saying that his 
modes of presentation differ, in that one is visual and the other memorial. Nonetheless, as a routine matter the character (as visual or as memorial) of modes of presentation is accessible to the thinker. How does this happen? A good question. A natural answer for the file account would seem to be that the thinker has access to the ER relation at the base of the file. So the file itself contains information about the ER relation on which it is based. For example, Earl's file on the Louvre when he first sees it includes a description 'being the $x$ I see before me'; his file when he remembers the building includes 'being the $x$ I once saw' or some such. Recanati could resist this idea and hold instead that only reflective thinkers have such access to ER relations, and perhaps claim that access comes in the form of a higher-order thought about the sources of one's information. I suspect this wouldn't get it right about lots of ordinary cases of unreflective people who reason in ways that are sensitive to the mode by which they acquire information. To handle the unreflective cases, some internalizing of the ER relation seems needed to account for the phenomena.

Given these two points (a) and (b), perhaps the files theorist might relent and allow some internalized contents concerning acquaintance. Perhaps one could do so without thereby going all the way to full Descriptivism, on which these grasped descriptive contents suffice to determine reference. But, equally, if we allow the internalization of some content relevant to reference determination, then some Descriptivist views may be in the clear. For instance, consider David Lewis's descriptivism. ${ }^{7}$ Lewis can argue that a causal relation is part of what does the reference fixing; and while a description grasped by the speaker doesn't fix reference all by itself, it does fix the character of our terms. This character, in combination with facts about the occasion of utterance and facts about causes, determines reference. These further facts are not represented in the content of the thought. Some of the reference fixing relation gets into the head, and some stays outside it, if you will. That doesn't seem implausible. Whatever we might think of the view, it seems that Recanati's view and a modified Descriptivism like Lewis's aren't so far apart on the issue

${ }^{7}$ Holton 2003. 
of internalized acquaintance relations.

\section{Files vs. competing accounts}

There are many other competing theories of reference and cognitive significance phenomena. For instance, on the Descriptivist side, there is Two-Dimensional Semantics, which develops a new account of sense or intension. ${ }^{8}$ And on the Singularist side there are Direct Reference theorists who want to handle many of the phenomena Recanati handles by invoking new kinds of truth-conditional content, instead of files or modes of presentation. ${ }^{9}$

How does the files account compare to these competing theories? The question is too large for full discussion here, but a couple of questions can frame further inquiry.

First, as we have seen, Recanati would set all Descriptivist theories aside:

'...what I objected to ... was not two-dimensionalism per se, but the descriptivist construal: the idea that the acquaintance relations which determine what a given thought is about are represented in the content of the thought...' (194).

Recanati notes that Jackson and Chalmers' Two-Dimensional Semantics does not suppose that epistemic intensions are represented in the content of thoughts (note 171), and in consequence, he seems to have no complaint against this Descriptivist view. But in that case, it seems we do not need a file framework to dispense with the relevant Descriptivist commitment. So what recommends a files-based approach?

This question becomes pressing when Recanati considers other accounts that dispense with senses or modes of presentation, and attempt to capture 'mental indexicality' (195) without the use of files. Among these, Recanati considers Lewis's centered worlds approach, and John Perry's token-reflexive approach. Recanati says the main problem is that each re-introduce the 'descriptivist commitment' (195) i.e. making reference fixing relations internal to the thought. I have discussed above whether Recanati himself can completely avoid

${ }^{8}$ Chalmers and Jackson 2001.

${ }^{9}$ Stalnaker 2010; Lewis 1983; Perry 2001; Kaplan 1989; Fine 2007. 
such a commitment, so I won't say more about this. But Recanati voices a different and more serious worry about the token-reflexive approach that I do want to discuss.

Briefly, the token-reflexive account holds that relations of speakers to token utterances help to determine a kind of reflexive content, over and above the subject matter content of the utterance. The hope is that we can appeal to the former in order to address various problems for direct reference theory.

Recanati raises an objection to the whole approach:

'If I say or think 'I am tired', and this is analysed as 'the utterer/thinker of $u$ is tired at the time of $u$ in the world of $u^{\prime}$, then I have referred to myself under the descriptive-relational mode of presentation 'the utterer/thinker of $u$ '. In the token-reflexive framework, every object of thought is referred to under such a descriptive-relational mode of presentation which exploits the object's relation to $u$. But what about $u$ itself ? Under which mode of presentation is it referred to?' (198)

Recanati considers possible ways for the token-reflexive theorist to articulate a suitable mode of presentation for $u$ ('this occurrence', or what have you), and argues that none work. He concludes that

'if one goes for reflexive modes of presentation, they must be treated as nondescriptive. At this point, clearly, we need a theory of nondescriptive modes of presentation - the sort of theory I have tried to provide - and the token-reflexive framework is of no help in this endeavour. So the reflexivist is in a rather bad situation: her account does not stand on its own feet and needs support from the account it is supposed to be an alternative to.' (198)

This is a serious charge. How might the token-reflexive theorist respond? Start here: Perry's actual answer to the question 'Under which mode of presentation is the utterance $u$ itself referred to?' is 'None. ${ }^{10}$ Rather, the utterance $u$ figures as a constituent of the proposition that expresses the reflexive content of the utterance. There is no description of $u$, or sense or mode of presentation under which the subject thinks of $u$ itself. (According to Perry, reflexive propositions are 'lumpy general propositions' in which the utterance is itself a constituent. ${ }^{11}$ )

\footnotetext{
${ }^{10}$ Perry (2001: 77).

${ }^{11}$ Perry (2001: 29, 77).
} 
If we avoid Recanati's conclusion that the token-reflexive theory is up the creek without a paddle, then it seems the question of why choose the files approach is still open. ${ }^{12}$

On this point I close with an observation. Often, Recanati's approach is to argue for the necessity of the files framework in light of the abject failure of other approaches. And there may in fact be places where one can insist that we are forced to invoke cognitive particulars (files or something else) in our explanations. For instance, one might argue that cognitive particulars are necessary in explaining what it is for one to think of something as being the same thing, or to engage in 'coreferential thinking. ${ }^{13}$ But it is also possible that one does not need to argue for the absolute untenability of other approaches in order to advocate in favor of the files framework. One could instead seek to articulate the distinctive advantages of the file model over other models.

${ }^{12}$ I'm not certain whether Recanati acknowledges this answer. He goes on to consider an alternative reply for the token-reflexivist, but I'm not certain it captures the account just sketched. Recanati writes:

'Instead of appealing to reflexive modes of presentation, he or she may appeal to super-direct reference, the sort of thing that Russell was after. In super-direct reference, there is no mode of presentation: the referent itself serves as its own vehicle, as it were. No mental file is needed to stand for the object in such a case, because the object itself is directly recruited as a thought constituent. This of course cannot be done with many objects, but with mental occurrences arguably it can' (198).

I'm not certain if Recanati is here talking about the answer Perry gives (that utterances are themselves constituents of reflexive propositions). But what is Recanati's concern about this approach? He writes:

'Although I have no knock down argument against this approach, I find it unsufficiently [sic] motivated and too much in the grip of a rather extreme Cartesian picture. Why not appeal instead to multiple anchors, corresponding to all the acquaintance relations in which we stand to objects of thought?'

I'm not sure how to understand the concern about Cartesianism, though the claim that we can go with the files account if we want to instead of going tokenreflexivist is of course true.

${ }^{13}$ The story here is a long one, and the fact that we have cognitive particulars is clearly not the whole of it. There are content-based competitors here too, we should note. For instance, Kit Fine 2007 thinks we can use content-based explanation for sameness of thinking as well. I'm not convinced one can do so, on pain of circularity worries, but that is a topic for another day. 
A prima facie advantage of the file model is that it holds out the possibility of using the same model to handle a bunch of problems and questions. For instance, we would like an account that explains what it is for one to think of something as being the same thing coreferential thinking. We would also like an account that identifies a stable public content for certain explanatory purposes (direct reference theory does a good job with this), and also handles coreference phenomena or Frege cases, empty names, and confused reference (direct reference theory runs into trouble with these). Some theorists favor mixed approaches. John Perry is a good example. He uses cognitive particulars (files) for some jobs, and reflexive content for other jobs: he uses files to explain what it takes to think coreferentially, but doesn't use them to handle Frege cases, preferring reflexive content for this purpose. If the files account can handle all of these problems, with a single model, that would seem a point in its favor.

All things considered, it would be good to hear more about the comparative advantages of the files account.

Krista Lawlor Building 90 room $92 \mathrm{M}$ Stanford University California 94305

United States krista.lawlor@stanford.edu

\section{References}

Chalmers, David and Jackson, Frank. 2001. Conceptual Analysis and Reductive Explanation. Philosophical Review 110, no. 3: 315-61.

Fine, Kit. 2007. Semantic Relationism. Wiley-Blackwell.

Holton, Richard. 2003. David Lewis's Philosophy of Language. Mind and Lanquage 18, no. 3: 286-8211.

Kaplan, David. Demonstratives: An Essay on the Semantics, Logic, Metaphysics, and Epistemology of Demonstratives and Other Indexicals. In Themes from Kaplan, ed. by Perry Almog, 614. Oxford: Oxford University Press, 1989

Kaplan, David. 1970. Dthat. Syntax and Semantics 9: 221-43.

Kripke, Saul A. Naming and Necessity. Wiley, 1991.

Lewis, David. 1983. Philosophical Papers: Volume I. Oxford University Press.

Marcus, Ruth Barcan. 1961. Modalities and Intensional Languages. Synthese 13, no. 4: 303-322.

Perry, John. 2001. Reference and Reflexivity. Stanford: CSLI Publications.

Searle, John R. 1983. Intentionality: An Essay in the Philosophy of Mind. Cambridge University Press. 
Stalnaker, Robert C. 2010. Our Knowledge of the Internal World. Reprint. Oxford University Press

Strawson, Peter. F. 2004. Logico-Linguistic Papers. Revised. Ashgate Pub Ltd. 